\title{
Association between Sociodemographic Factors and Diarrhea in Children Under 5 Years in Rwanda
}

\author{
Umuhoza Claudine ${ }^{1,2}$, Ju Yeong Kim¹, Eun-Min Kim¹, Tai-Soon Yong ${ }^{1,2, *}$ [i] \\ ${ }^{1}$ Department of Environmental Medical Biology, Institute of Tropical Medicine, Arthropods of Medical Importance Resource Bank, Yonsei University \\ College of Medicine, Seoul 03722, Korea; '2Department of Global Health Security, Graduate School of Public Health, Yonsei University, Seoul 03722 , \\ Korea
}

\begin{abstract}
Diarrheal disease is the second leading cause of mortality and morbidity in children under 5 years old worldwide, and is the most common cause of malnutrition in sub-Saharan Africa. In Rwanda, diarrhea is the third leading cause of death in children under 5 years old. This study examined the association between sociodemographic factors and diarrhea in children under 5 years using the data of 7,474 households in the 2014-2015 Rwanda Demographic and Health Survey. Overall prevalence of diarrhea in this study was $12.7 \%$ in children. An increased risk for diarrhea was found for children aged 12-23 months (odds ratio $(\mathrm{OR})=4.514)$, those with a low economic status $(\mathrm{OR}=1.64)$, those from the Western province $(\mathrm{OR}=1.439)$, those with poorly-educated mothers $(\mathrm{OR}=5.163)$, and those with families engaged in agricultural activities $(\mathrm{OR}=1.624)$. In conclusion, sociodemographic factors significantly affect the risk of developing diarrhea in children under 5 years in Rwanda. Designing and implementing health education promoting awareness of early interventions and rotavirus vaccination are essential to reduce diarrheal diseases for the Rwandan community.
\end{abstract}

Key words: Diarrhea, children, Rwanda

Diarrheal disease is the second leading cause of morbidity and mortality in children under 5 years, worldwide. According to the World Health Organization (WHO), around 1.7 billion cases of diarrhea in children are reported annually, which result in 525,000 child deaths per year [1]. Around the world, 780 million people live without clean water, about 2.5 million people live in an environment with poor sanitation, and are from developing countries such as South-Asia and sub-Saharan Africa where the majority of children experience at least 3 episodes of diarrhea each year [1]. According to a study published in 2016, the burden of diarrhea is still a challenge and a cause of death in both adults over 70 years and children under 5 years [2].

In Rwanda, a small landlocked country in Central-East Africa with a population of 12.5 million, diarrheal disease is ranked as the third leading cause of mortality in children under 5 years and was responsible for $18.3 \%$ of childhood deaths in 2015 . Additionally, around $45 \%$ of the population

\footnotetext{
- Received 10 September 2020, revised 7 January 2021, accepted 18 January 2021. *Corresponding author (tsyong212@yuhs.ac) (c) 2021, Korean Society for Parasitology and Tropical Medicine This is an Open Access article distributed under the terms of the Creative Commons Attribution Non-Commercial License (https://creativecommons.org/licenses/by-nc/4.0) which permits unrestricted non-commercial use, distribution, and reproduction in any medium, provided the original work is properly cited.
}

in Rwanda are under 18 years old, making this a significant concern [3]. Diarrheal disease increases the country and family's economic burden. A study conducted in Rwanda showed that the burden of diarrheal disease was 101 US dollars per family per year, despite $93 \%$ of the general population being covered by health insurance [4]. Another study showed that the risk factors of diarrhea in children under 5 years were lack of clean water and inadequate hygiene and sanitation [5]. Therefore, there is a need to determine the implications of sociodemographic factors in the development of diarrhea in vulnerable groups to increase community awareness regarding prevention measures of diarrhea, as well as management and treatment, in the hopes of decreasing morbidity and mortality in this population. The aim of this study was to assess the association between sociodemographic factors and diarrhea in children under 5 years in Rwanda.

The study was a secondary data analysis of the 2014-2015 Demographic and Health Survey (DHS) - a population-based health survey in Rwanda. The study included data from 7,474 households with women between 15-49 years old who had children under 5 years. The Rwanda DHS was conducted using 3 different questionnaires: (1) household questionnaire, (2) women's questionnaire, and (3) men's questionnaire. The children's health information was collected using the house- 
hold questionnaire on the household's characteristics from both parents. This study was performed by using the household's datasets which recorded the sociodemographic characteristics of households with a live childbirth within the past 5 years. Before performing the research, the abstract of the study was sent to the DHS program to obtain approval to use the data from Rwanda. All DHS data were treated anonymously and confidentially.

Among 7,474 women with children less than 5 years old, 4,192 (56.1\%) were 25-34 years old (Table 1). Regarding the mother's education level, $14.2 \%$ were never educated. For the province of residence, $25.1 \%$ of women were from the Western province, $24.6 \%$ were from the Southern province, $24.6 \%$ were from the Eastern province, $13.9 \%$ were from the North province, while $11.7 \%$ were from Kigali city. Majority of the women resided in rural areas (78.1\%) compared to urban areas (21.9\%). According to the wealth index category, most of the women were living in the poorest category $(23.8 \%)$, followed by the poorer category $(20.9 \%)$, the middle category (19.0\%), the richer category (17.1\%), and the richest category (19.1\%). Regarding marital status, the majority of women were either married (53.6\%) or were unmarried but lived with their partner (28.9\%). Among 7,474 children, 50.4\% were male and $49.6 \%$ were female. Of 3615 children with data for age, $11.7 \%$ were $<6$ months old, $9.8 \%$ were $6-11$ months old, $20.7 \%$ were $12-23$ months old, $20.9 \%$ were $24-34$ months old, and $36.9 \%$ were $35-59$ months old. Diarrhea was reported in $12.7 \%$ of the children.

There was a significant association between diarrhea and the mother's age, marital status, province of residence, type of residence, education level of the mother and father, wealth index, and occupation with a $P$-value less than 0.05 (Table 1). There was no association found between literacy, religion, and number of children in the households.

Multivariate logistic analysis was conducted to demonstrate the relationship between sociodemographic factors and diarrheal diseases in children under 5 years old (Table 2). The variable with a $P$-value less than 0.05 in the bivariate analysis was included in the multivariate analysis. Children aged between 24-34 months, 12-23 months, and 35-59 months were 2.652, 4.514, and 2.340 times more at risk for diarrhea than those $<6$ months, respectively. Considering the wealth index of the family, children in the poorer and poorest categories were 1.64 and 1.592 times more at risk to develop diarrhea than children from the richest category, respectively. The risk of devel-
Table 1. Association of sociodemographic characteristics of respondents with diarrhea

\begin{tabular}{|c|c|c|c|}
\hline \multirow{2}{*}{ Variables } & \multicolumn{2}{|c|}{ Diarrhea } & \multirow{2}{*}{$P^{*}$} \\
\hline & Total & Yes (\%) & \\
\hline \multicolumn{4}{|l|}{ Mother's age (yr) } \\
\hline $15-19$ & 142 & $17(12)$ & 0.028 \\
\hline $20-24$ & 1,281 & $187(14.6)$ & \\
\hline $25-34$ & 4,192 & $488(11.6)$ & \\
\hline $35-49$ & 1,859 & $213(11.5)$ & \\
\hline \multicolumn{4}{|l|}{ Marital status } \\
\hline Never in union & 642 & $95(14.8)$ & 0.030 \\
\hline Married & 4,009 & $439(11)$ & \\
\hline Living with partner & 2,160 & $2,71(12.5)$ & \\
\hline Widowed & 145 & $18(12.4)$ & \\
\hline Divorced & 190 & $34(17.9)$ & \\
\hline Separated & 328 & 48 (14.6) & \\
\hline \multicolumn{4}{|l|}{ Province } \\
\hline Kigali city & 875 & $76(8.7)$ & $<0.001$ \\
\hline South & 1,841 & $228(12.4)$ & \\
\hline West & 1,879 & $274(14.6)$ & \\
\hline North & 1,039 & $113(10.9)$ & \\
\hline East & 1,840 & $214(11.6)$ & \\
\hline \multicolumn{4}{|l|}{ Residence } \\
\hline Urban & 1,635 & $168(10.3)$ & 0.010 \\
\hline Rural & 5,839 & 737 (12.6) & \\
\hline \multicolumn{4}{|l|}{ Mother's education level } \\
\hline Uneducated & 1,067 & $145(13.6)$ & $<0.001$ \\
\hline Primary & 5,355 & $669(12.5)$ & \\
\hline Secondary & 853 & $86(10.1)$ & \\
\hline Higher & 199 & $5(2.5)$ & \\
\hline \multicolumn{4}{|l|}{ Wealth index } \\
\hline Poorest & 1,780 & $271(15.2)$ & $<0.001$ \\
\hline Poorer & 1,565 & $226(14.4)$ & \\
\hline Middle & 1,421 & $162(11.4)$ & \\
\hline Richer & 1,277 & $130(10.2)$ & \\
\hline Richest & 1,431 & $116(8.1)$ & \\
\hline \multicolumn{4}{|l|}{ Occupation } \\
\hline Not working & 498 & $46(9.2)$ & 0.028 \\
\hline Professional & 381 & $28(7.3)$ & \\
\hline Sales & 712 & 90 (12.6) & \\
\hline Agricultural & 5,499 & $703(12.8)$ & \\
\hline Domestic & 93 & $9(9.7)$ & \\
\hline Manual job & 289 & $29(12.1)$ & \\
\hline \multicolumn{4}{|l|}{ Literacy } \\
\hline Cannot read at all & 1,653 & $231(14)$ & 0.098 \\
\hline $\begin{array}{l}\text { Able to read only parts of a } \\
\text { sentence }\end{array}$ & 651 & $73(11.2)$ & \\
\hline Able to read whole sentences & 5,155 & $601(11.7)$ & \\
\hline Visually impaired & 6 & 0 & \\
\hline \multicolumn{4}{|l|}{ Religion } \\
\hline Catholic & 2,683 & $325(12.1)$ & 0.0698 \\
\hline Protestant & 3,636 & 446 (36.3) & \\
\hline Adventist & 898 & 98 (10.9) & \\
\hline Muslim & 163 & $21(12.9)$ & \\
\hline Jehovah's Witness & 48 & $8(16.7)$ & \\
\hline No religion & 39 & $7(17.9)$ & \\
\hline Other & 2 & 0 & \\
\hline
\end{tabular}

(Continued to the next page) 
Table 1. Continued

\begin{tabular}{|c|c|c|c|}
\hline \multirow{2}{*}{ Variables } & \multicolumn{2}{|c|}{ Diarrhea } & \multirow{2}{*}{$P^{*}$} \\
\hline & Total & Yes (\%) & \\
\hline \multicolumn{4}{|c|}{ Number of living children } \\
\hline 0 & 105 & $12(11.4)$ & 0.840 \\
\hline 1 & 3,358 & $399(11.9)$ & \\
\hline 2 & 3,146 & $391(12.4)$ & \\
\hline 3 & 796 & 97 (12.2) & \\
\hline 4 & 53 & $6(11.3)$ & \\
\hline 5 & 9 & 0 & \\
\hline 7 & 7 & 0 & \\
\hline \multicolumn{4}{|c|}{ Child's age (month) } \\
\hline$<6$ & 423 & $33(7.8)$ & $<0.001$ \\
\hline $6-11$ & 354 & $60(16.9)$ & \\
\hline $12-23$ & 747 & $181(24.2)$ & \\
\hline $24-34$ & 757 & $109(14.4)$ & \\
\hline $35-59$ & 1,334 & $76(5.7)$ & \\
\hline \multicolumn{4}{|l|}{ Child's sex } \\
\hline Male & 3,766 & $476(12.6)$ & 0.156 \\
\hline Female & 3,708 & $429(11.6)$ & \\
\hline \multicolumn{4}{|c|}{$\begin{array}{l}\text { Husband/partner's education } \\
\text { level }\end{array}$} \\
\hline Uneducated & 1,134 & $154(13.6)$ & $<0.001$ \\
\hline Primary & 4,778 & 587 (12.3) & \\
\hline Secondary & 619 & $49(7.9)$ & \\
\hline Higher & 270 & $13(4.8)$ & \\
\hline
\end{tabular}

*, Chi-square test applied.

oping diarrhea was 1.439 times higher in children from the Western province compared to children from Kigali city. The occupation of the women in the family was found to have an impact on diarrhea in children. Children from families working in agricultural activities were 1.624 times more at risk than those from families with a mother who did not work and remained at home. In the case of uneducated women, their children were 5 times more at risk for developing diarrhea when compared with those whose mothers completed higher education.

The prevalence of diarrhea was found to be $12.7 \%$ in children under 5 years, which is slightly lower than the 2010 DHS findings of $13.1 \%$ [6]. It is also lower than a cluster study conducted in the health facilities in Nyarugenge District, Rwanda which showed a $26 \%$ prevalence of diarrhea [5]. The decrease in diarrhea prevalence in Rwanda may be due to the increasing access to clean water and improved sanitation in communities, and the increased access to medical services due to better health insurance coverage for the general population. The prevalence of diarrhea in Rwanda is also lower compared to the nomadic population in Ethiopia, which showed a 26.1\%
Table 2. Multivariate logistic regression analysis of diarrhea with sociodemographic factors

\begin{tabular}{|c|c|c|c|}
\hline Variables & Odds ratio & $95 \% \mathrm{Cl}$ & $P^{*}$ \\
\hline \multicolumn{4}{|l|}{ Child's age } \\
\hline$<6 \mathrm{~m}^{\mathrm{a}}$ & 1 & & \\
\hline $6-11$ & 1.404 & $0.85-2.30$ & 0.180 \\
\hline $12-23$ & 4.514 & $3.04-6.68$ & $<0.001^{*}$ \\
\hline $24-34$ & 2.652 & $2.65-4.23$ & $<0.001^{*}$ \\
\hline $35-59$ & 2.340 & $1.58-3.45$ & $<0.001^{*}$ \\
\hline \multicolumn{4}{|l|}{ Marital status } \\
\hline No longer living together ${ }^{a}$ & 1 & & \\
\hline Married & 0.837 & $0.59-1.17$ & 0.306 \\
\hline Living with partner & 0.869 & $0.61-1.22$ & 0.421 \\
\hline Widowed & 0.895 & $0.49-1.62$ & 0.715 \\
\hline Divorced & 1.352 & $0.82-2.22$ & 0.237 \\
\hline \multicolumn{4}{|l|}{ Wealth index } \\
\hline Poorest & 1.592 & $1.15-2.19$ & $0.005^{\star}$ \\
\hline Poorer & 1.640 & $1.19-2.24$ & $0.002^{*}$ \\
\hline Middle & 1.274 & $0.92-1.76$ & 0.143 \\
\hline Richer & 1.109 & $0.80-1.53$ & 0.528 \\
\hline Richest $^{a}$ & 1 & & \\
\hline \multicolumn{4}{|l|}{ Mothers' education level } \\
\hline Uneducated & 5.163 & $1.16-22.92$ & $0.031^{*}$ \\
\hline Primary & 4.736 & $1.09-20.54$ & $0.038^{*}$ \\
\hline Secondary & 4.098 & $0.94-17.75$ & 0.059 \\
\hline Higher $^{a}$ & 1 & & \\
\hline \multicolumn{4}{|l|}{ Type of residence } \\
\hline Urban $^{a}$ & 1 & & \\
\hline Rural & 0.760 & $0.52-1.09$ & 0.139 \\
\hline \multicolumn{4}{|l|}{ Province } \\
\hline Kigali citya & 1 & & \\
\hline South & 1.232 & $0.87-1.72$ & 0.226 \\
\hline West & 1.439 & $1.03-2.00$ & $0.032^{*}$ \\
\hline North & 1.144 & $0.79-1.64$ & 0.467 \\
\hline East & 1.193 & $0.85-1.67$ & 0.305 \\
\hline \multicolumn{4}{|l|}{ Occupation } \\
\hline Not working ${ }^{a}$ & 1 & & \\
\hline Professional & 1.007 & $0.58-1.73$ & 0.979 \\
\hline Sales & 1.316 & $0.69-2.49$ & 0.401 \\
\hline Agricultural & 1.624 & $1.00-2.62$ & $0.048^{*}$ \\
\hline Domestic & 1.160 & $0.74-1.80$ & 0.511 \\
\hline Manual job & 1.317 & $0.53-3.23$ & 0.548 \\
\hline \multicolumn{4}{|l|}{ Husband's education level } \\
\hline Uneducated & 1.517 & $0.75-3.03$ & 0.238 \\
\hline Primary & 1.483 & $0.76-2.89$ & 0.248 \\
\hline Secondary & 1.059 & $0.53-2.10$ & 0.870 \\
\hline Higher $^{\mathrm{a}}$ & 1 & & \\
\hline
\end{tabular}

a, reference; *, $P$-value $<0.05$.

prevalence according to another study [7]. Findings also show that there was a lower prevalence of diarrhea in Northern $(14.5 \%)$ and Eastern parts (22.5\%) of Ethiopia [8,9].

In this study, significant association between diarrhea and age was found, as children aged 12-23 months were 4 times 
more at risk of developing diarrhea than those aged $<6$ months, which was similar to the results of a study done in Pakistan [10]. Younger infants would be protected against diarrheal diseases by different mechanisms such as maternal antibodies obtained through breastfeeding. The children become less protected by maternal antibodies after weaning.

Living in the Western province was also found to be riskier for developing diarrhea, as this part of Rwanda is situated near lake Kivu, and some families residing here use the contaminated water from the lake for drinking and food preparation.

The children from poor families had a higher risk of developing diarrhea than children from middle, richer, and richest families. This is likely due to inadequate hygiene and sanitation, lack of clean water, lack of knowledge on diarrhea prevention, inappropriate disposal of stool, and living near unsafe ponds and wells [5]. Families involved in agricultural activities were found to be at higher risk of diarrhea due to soiltransmitted parasites, as the farmers use contaminated water for crop irrigation and food preparation. A study done in India shows a close relationship between irrigation water quality and the incidence of diarrhea in farming households [11].

A mother's lack of education was found to increase the risk for the development diarrhea in children, since an educated mother is more likely to be empowered to take care of her children and her family, which is the expectable result. Previous studies have shown that highly educated mothers' children were at low risk of morbidity and mortality due to diarrhea because they have necessary knowledge and practice good hygiene and sanitation $[10,12]$. Therefore, educated mothers are very important for the wellbeing and health status of children under 5 years and are significant predictors of good development of their children [13].

WHO recommends the rotavirus vaccination in children for protection against diarrhea. Rotavirus vaccine was introduced in Rwanda in 2012 and since its introduction, the number of cases of non-bloody diarrhea decreased by $17-29 \%$ and the active surveillance of the rotavirus showed a reduction of $61-70 \%$ of gastroenteritis cases in 2013-2014 in every age group [14]. The mortality associated with the rotavirus has decreased considerably since the introduction of its vaccine in Rwanda [15].

In conclusion, this study found that among various sociodemographic factors, the child's age, wealth index, education attainment of the mother, province of residence, and the family's involvement in agricultural activities are closely related to the risk of developing diarrhea in children less than 5 years in
Rwanda. Children from a poor family had a higher risk compared to more well-off families, and mothers with lower educational attainment placed their children at higher risk of diarrhea. To decrease diarrheal morbidity and mortality, designing and implementing health education and promoting awareness of simple early interventions to treat children with diarrhea are essential in the Rwandan community.

\section{CONFLICT OF INTEREST}

The authors have no conflicts of interest to declare.

\section{REFERENCES}

1. Aziz FAA, Ahmad NA, Razak MAA, Omar M, Kasim NM, Yusof M, Sooryanarayana R, Jamaludin R, Ying CY. Prevalence of and factors associated with diarrhoeal diseases among children under five in Malaysia: a cross-sectional study 2016. BMC Public Health 2018; 18: 1363. https://doi.org/10.1186/s12889-0186266-z

2. Collaborators G 2016 DD. Estimates of the global, regional, and national morbidity, mortality, and aetiologies of diarrhoea in 195 countries: a systematic analysis for the Global Burden of Disease Study 2016. Lancet Infect Dis 2018; 18: 1211-1228. https://doi.org/10.1016/S1473-3099(18)30362-1

3. UNICEF Rwanda 2017. Children's Rights and Sustainable Development in Rwanda: A Situation Analysis. 2017, pp 1-128.

4. Ngabo F, Mvundura M, Gazley L, Gatera M, Rugambwa C, Kayonga E, Tuyishime Y, Niyibaho J, Mwenda JM, Donnen P, Lepage P, Binagwaho A, Atherly D. The Economic Burden Attributable to a Child's Inpatient Admission for Diarrheal Disease in Rwanda. PLoS One 2016; 11: e0149805. https://doi.org/10.1371/journal. pone. 0149805

5. Nsabimana J, Mureithi C, Hbatu M. Factors Contributing to Diarrheal Diseases among Children Less than Five Years in Nyarugenge District, Rwanda. J Trop Dis 2017; 5: 3. https://doi.org/10.4172/2329891X.1000238

6. O'Connell B, Quinn M, Scheuerman PR. Risk factors of diarrheal disease among children in the East African countries of $\mathrm{Bu}$ rundi, Rwanda and Tanzania. Glob J Med Public Heal 2017; 6.

7. Woldu W, Bitew BD, Gizaw Z. Socioeconomic factors associated with diarrheal diseases among under-five children of the nomadic population in northeast Ethiopia. Trop Med Health. Trop Med Health 2016; 44: 40. https://doi.org/10.1186/s41182-0160040-7

8. Mengistie B, Berhane Y, Worku A. Prevalence of diarrhea and associated risk factors among children under-five years of age in Eastern Ethiopia A cross-sectional study. Open J Prev Med 2013; 3: 446-453. https://doi.org/10.4236/ojpm.2013.37060

9. Wasihun AG, Dejene TA, Teferi M, Marugán J, Negash L, Yemane 
D, McGuigan KG. Risk factors for diarrhoea and malnutrition among children under the age of 5 years in the Tigray Region of Northern Ethiopia. PLoS One 2018; 13: e0207743. https://doi. org/10.1371/journal.pone.0207743

10. Irfan M, Zaidi SMH, Waseem HF. Association of socio-demographic factors with diarrhea in children less than five years: a secondary analysis of multiple indicator cluster survey SINDH 2014. Pakistan J Public Heal 2017; 7: 85-89. https://doi.org/10. 32413/pjph.v7i2.39

11. Falkenberg T, Saxena D. Impact of wastewater-irrigated urban agriculture on diarrhea incidence in Ahmedabad, India. Indian J community Med 2018; 43: 102-106. https://doi.org/10.4103/ ijcm.IJCM_192_17

12. Bado AR, Susuman AS, Nebie EI. Trends and risk factors for childhood diarrhea in sub-Saharan countries (1990-2013): assessing the neighborhood inequalities. Glob Health Action 2016; 9: 30166. https://doi.org/10.3402/gha.v9.30166

13. Desmennu AT, Oluwasanu MM, John-Akinola YO, Oladunni O,
Adebowale SA. Maternal education and diarrhea among children aged 0-24 months in Nigeria. Afr J Reprod Health 2017; 21: 27-36. https://doi.org/10.29063/ajrh2017/v21i3.2

14. Ngabo F, Tate JE, Gatera M, Rugambwa C, Donnen P, Lepage P, Mwenda JM, Bingwaho A, Parashar UD. Effect of pentavalent rotavirus vaccine introduction on hospital admissions for diarrhoea and rotavirus in children in Rwanda: a time-series analysis. Lancet Glob Health 2016; 4: 129-136. https://doi.org/10.1016/S2214109X(15)00270-3

15. Troeger C, Khalil IA, Rao PC, Cao S, Blacker BF, Ahmed T, Armah G, Bines JE, Brewer TG, Colombara DV, Kang G, Kirkpatrick BD, Kirkwood CD, Mwenda JM, Parashar UD, Petri Jr WA, Riddle MS, Steele AD, Thompson RL, Walson JL, Sanders JW, Mokdad AH, Murray CJL, Hay SI, Reiner Jr RC. Rotavirus vaccination and the global burden of rotavirus diarrhea among children younger than 5 years. JAMA Pediatr 2018; 172: 958-965. https://doi.org/ 10.1001/jamapediatrics.2018.1960 
